\title{
Internal Logic of Water Level and Shipping Logistics System based on System Dynamics
}

\author{
Ting Liu ${ }^{1, a}$ \\ ${ }^{1}$ Economics and Management School, Jiujiang University, Jiujiang, Jiangxi, 332005, China \\ aemail: 515501708@qq.com
}

Keywords: Shipping Logistics; System Dynamics; Water Level

\begin{abstract}
Affected by the global climate change, storms, droughts and other extreme weather occur frequently in recent years. This extreme climate affects the Yangtze River a lot, leading to extreme water levels of Yangtze River occurrence frequently. Changes in extreme water level of the Yangtze River have a significant adverse impact on shipping transport efficiency, transport safety and economic of the Yangtze River shipping. Reveal the internal logic between water level and shipping logistics system, is the key to study problems of shipping logistics system. This paper studies the internal structure of shipping logistics system and analyzes the influence of transfer process from water level to shipping logistics system. It provides a new way of studying for the development of waterway regulation, ship type development, ship transport organization, shipping safety management, port construction and operation, etc.
\end{abstract}

\section{Introduction}

Combined with the definition of shipping and logistics system, can be considered shipping logistics system means to achieve the "goods" of spatial displacement, the ship as a carrier completes two or more elements of logistics (transport, storage, handling, handling, packaging, distribution processing, distribution, information processing, etc.) in the process of logistics services. These elements of logistics consist of independent and interrelated organic aggregates.

Broadly speaking, shipping logistics system consists of shipping logistics supply subsystem, shipping logistics demand subsystem and external support subsystem. Because shipping logistics need subsystem limited by supply subsystem, which is reflected in the actual shipping freight volume, expressed as freight volume is always less than or equal to shipping demand, and therefore can be considered, the narrow shipping logistics system means shipping logistics supply subsystem.

Production subsystem is key to the whole shipping logistics system, ships, ports and waterways are the basic conditions of shipping logistics, they achieve the goal of shipping logistics through the coordination of balance and cooperation between them; organization subsystem reasonably configures resources, effectively organizes production process of shipping logistics; security subsystem provides some safeguard measures, such as technology, security, legal, information, these are to complete production tasks[1]. The framework of shipping logistics supply system shown in Figure 1:

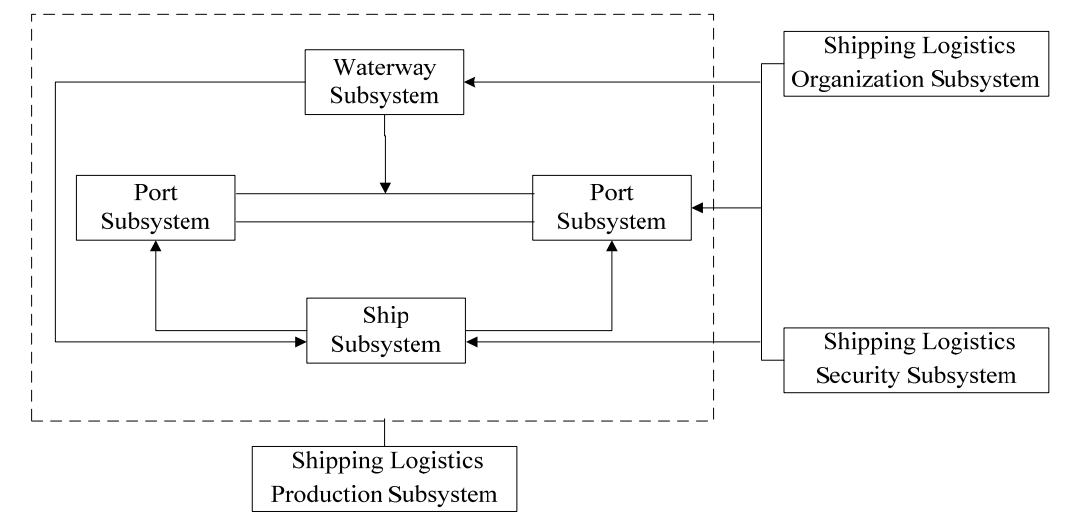

Fig.1. Frame chart of shipping logistics supply subsystem 


\section{Description of System Dynamics}

System dynamics believes behavioral patterns and characteristics of the system which depend on its internal structure, it is to understand and resolve problems of system through a feedback mechanism of information, suitable for solving complex causality of system which changes over time [2].

\section{Modeling Steps}

The first step, observes reality system, and extracts representative information, thereby establishes a basic framework model; the second step, defines constraints and boundary conditions of the system, and builds a concrete model, studies the internal structure of the system and analyzes the feedback mechanisms between global and local; the third step is to collect the necessary data for quantitative analysis, analyzes the dynamic evolution of the system, predicts the future of the system and propose a solution.

\section{Feedback Mechanism}

Each system exists the internal feedback structure and mechanism, which is the core idea of system dynamics. Suppose there is a causal relationship between the two variables $\mathrm{X}$ and $\mathrm{Y}, \mathrm{X}$ is the cause, $\mathrm{Y}$ is the result, use the line with arrows to indicate a causality, that $\mathrm{X}$ affects $\mathrm{Y}$. Each causal chain has polarity, positive $(+)$ or negative $(-)$, a positive polarity represents $\mathrm{Y}$ will increase (decrease) when $\mathrm{X}$ increases (decreases), and vice versa. As shown in Figure 2.

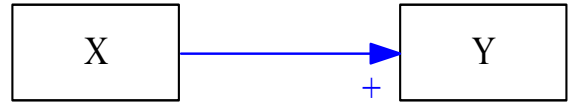

(a) Negative polarity

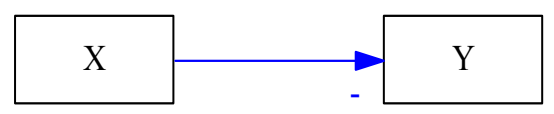

(b) Positive polarity

Fig.2. The causality between the two variables

Another aspect of feedback mechanism is feedback, it means $\mathrm{X}$ affects $\mathrm{Y}$, in turn $\mathrm{Y}$ influences $\mathrm{X}$ through a series of causal chain, that reasons cause results, then the results constitute new reasons. A feedback loop has polarity, it decided the superimposed effect of the causal chain polarity. The number of negative causal chain is odd in a feedback loop, then the feedback loop is negative, the negative feedback loop is to seek a balance, constantly revises system state, brings them closer to the target of system, called self-adjustment, the negative feedback circuit diagram shown in Figure 3(a):

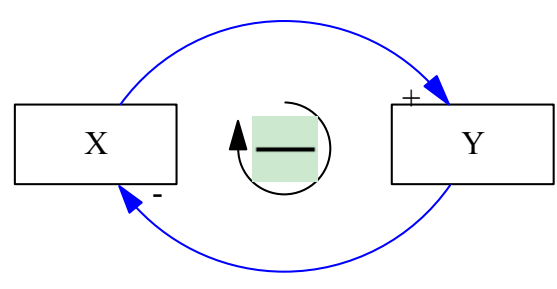

(a) Negative feedback

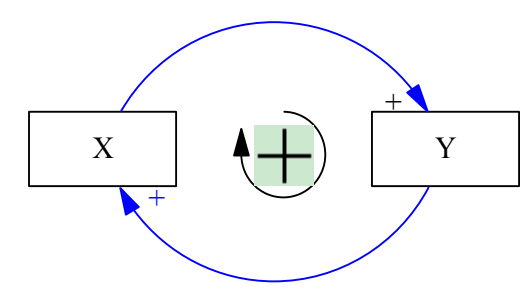

(b) Positive feedback

Fig.3. Feedback circuit diagram

When the number of positive polarity or negative polarity causal chain in the feedback loop is even number, then the feedback loop is positive, a positive feedback loop produces an increase the effect of change, called self-growth, and its positive feedback loop diagram can expressed as shown in Figure 3(b):

We should analyze the perspective of the whole system, a complete feedback system should include links of $\mathrm{X}$ and $\mathrm{Y}$ or $\mathrm{Y}$ and $\mathrm{X}$, then we may get a correct analysis conclusions. 


\section{The Goals of Shipping Logistics System}

The goals of shipping logistics system can be expressed as: the supply of shipping logistics system actively coordinates with the changing of demand. The word "actively" represents as supply should meet the demand of shipping logistics, and supply should also be a guide, induce and restrictive requirements.

\section{Shipping logistics system boundary}

According to the analysis of shipping logistics system, the boundary of shipping logistics system includes shipping logistics supply subsystem, shipping logistics demand subsystem and external support subsystem. Moreover shipping logistics supply subsystem is further divided into shipping logistics production subsystem, organization subsystem and security subsystem. These subsystems are endogenous variables of shipping logistics system, water level is a natural environmental factor, can be considered as exogenous variable. According to the principles of system dynamics, can establish major causal diagram of supply and demand balance of shipping logistics system[3], as shown in Figure 4:

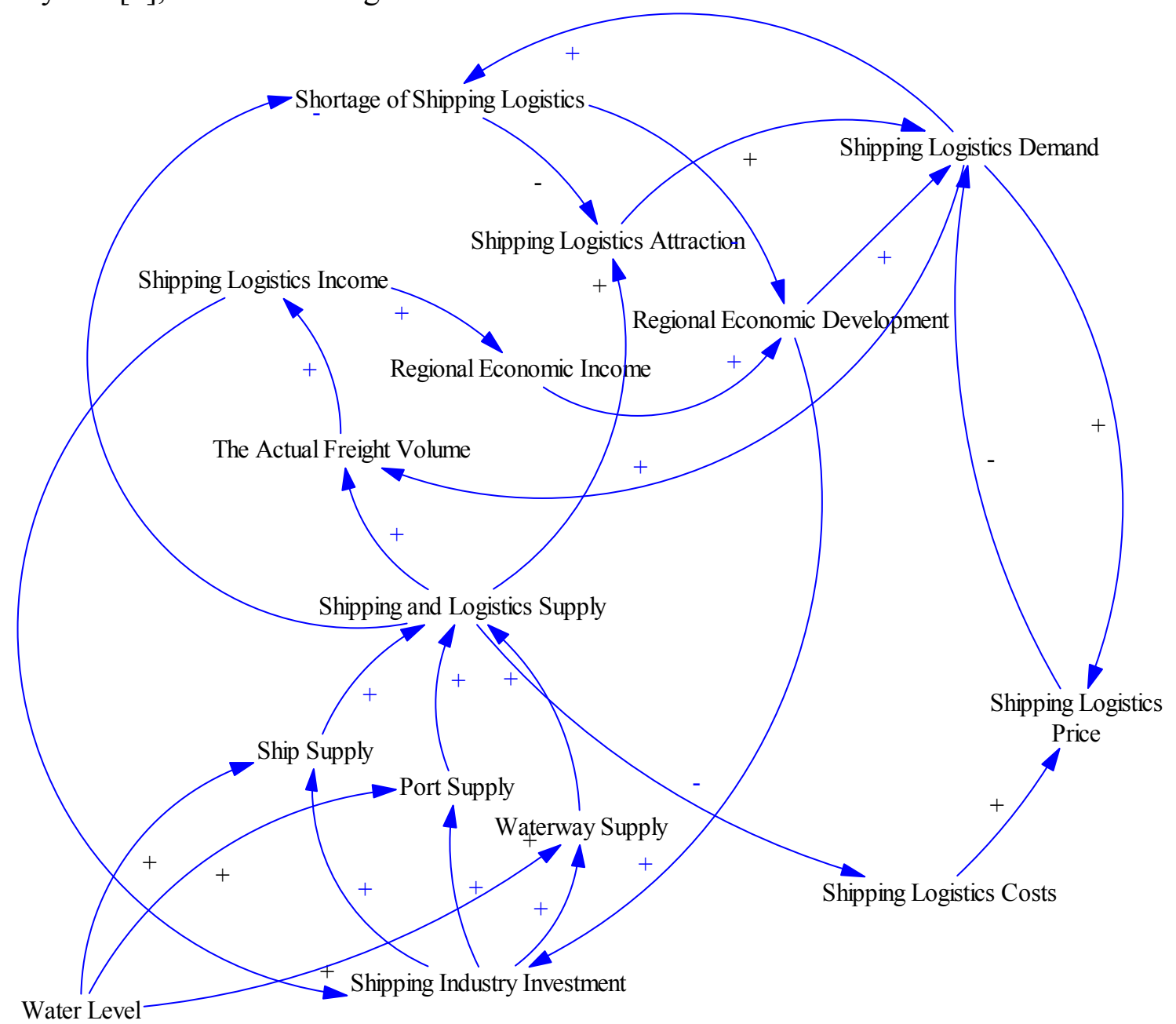

Fig.4. The mainly causal diagram of shipping logistics system

The function of shipping logistics system is to provide shipping logistics services for passengers and freight demands, supply subsystem enables spatial displacement of passengers and freight in the process of coordinating demand. Through analysis, the presence of shipping logistics system mainly exists several causal feedback loops as follows: 


\section{1) Self-adjusting Ring of Shipping Logistics Demand}

Self-adjusting ring of shipping logistics demand expresses as two negative feedback loops which affects shipping logistics demand, shown in Figure 5. The first feedback loop shows the development of shipping logistics demand will bring a shortage of shipping logistics capability, the faster development, the larger shortage, this shortage affects economic development of corresponding zone, then finally limits shipping logistics demand; The second shows: the faster development of shipping logistics demand, the greater shortage of shipping logistics capability, so the attractiveness of shipping will be declined, and ultimately affects the demand of shipping logistics. The more supply of shipping logistics, the less shortage of shipping logistics capability, the change of water level directly affects the shipping logistics supply capacity, when water level becomes high, supply capacity of shipping logistics will enhance, water level becomes low, supply capacity of shipping logistics will become weaker. Thus, the development of shipping logistics demand is not endless, which has self-regulating function.

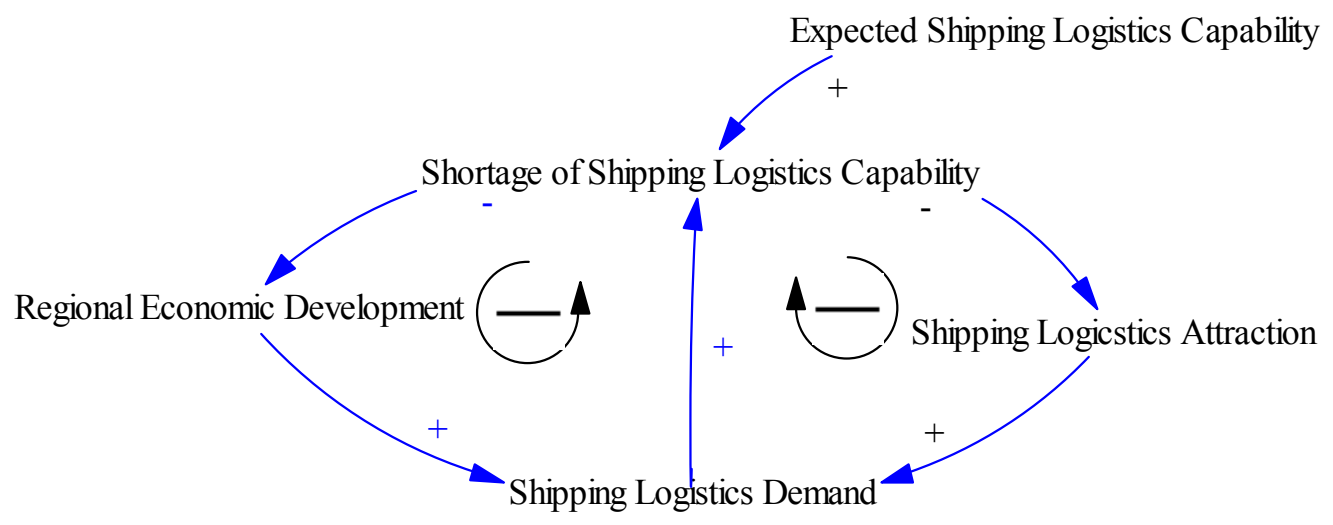

Fig.5. Self-adjusting ring of shipping logistics demand

\section{2)Self-growth Ring of Shipping Logistics Demand}

Self-growth ring of shipping logistics demand shown in Figure 6, is composed of two positive feedback loops. The first positive feedback loop expresses as enhancing the attractiveness of shipping logistics by increasing the supply of shipping logistics, in order to increase demand, and in turn improved the actual freight volume of shipping logistics, it makes more investment in the shipping industry, which increases shipping logistics supply in turn. Obviously, high water level will increase shipping logistics supply; the second positive feedback loop expresses as increasing shipping logistics demand by improving national economy, and an increase in shipping logistics demand influences the development of regional economy by increasing the actual freight volume, and thus shipping logistics demand shows an self -increasing trend [3].

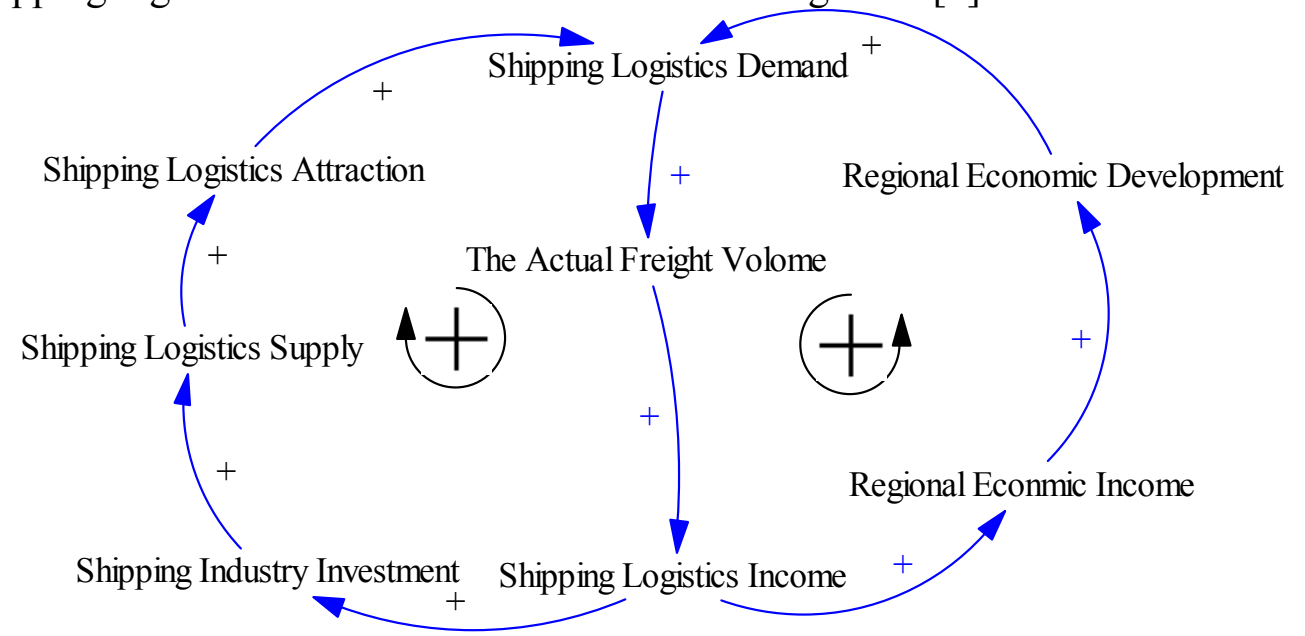

Fig.6. Self- growth ring of shipping logistics demand 


\section{3) Self-growth Ring of Shipping Logistics Supply}

Self-growth ring of shipping logistics supply is composed of two positive feedback loops, as shown in Figure 7, The first positive feedback loop shows the increase of shipping logistics supply depends on the development of regional economy, and only when the area develops the economy, the government will increase the investment in shipping logistics industry, and thus pulls the supply of shipping logistics; the second positive feedback loop represents as the regional economic development will increase government investment in the shipping industry, the increase of shipping logistics supply will reduce the shortages of shipping logistics capacity, the smaller the shortage, is more conducive to the development of regional economy, and ultimately enhances the supply of shipping logistics.

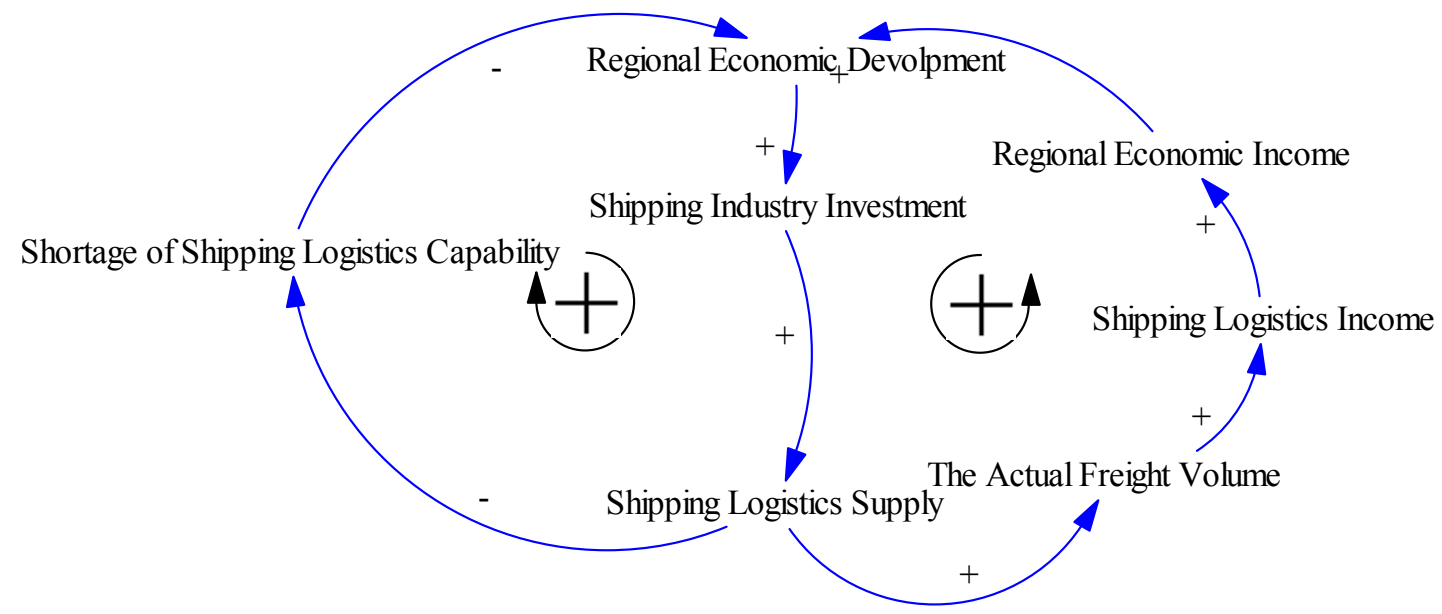

Fig.7. Self-growth ring of shipping logistics supply

\section{4) Demand and Supply Coordination Ring of Shipping Logistics}

There is a coordinated relationship between demand and supply of shipping logistics, the increase of shipping logistics supply will reduce shipping logistics cost and price, to guide and induce demand of shipping logistics, but increases the demand will increase the shortage of shipping logistics capability, restricts the development of regional economy, results in inadequate investment in shipping industry, not only affects the inputs of shipping logistics supply, but also inhibits shipping logistics demand. In this negative feedback loop, water level as a system exogenous variable affects shipping logistics supply, and expects water level is expected to reach the target of system, the exogenous variables can be affected by way of policies, as shown in Figure 8:

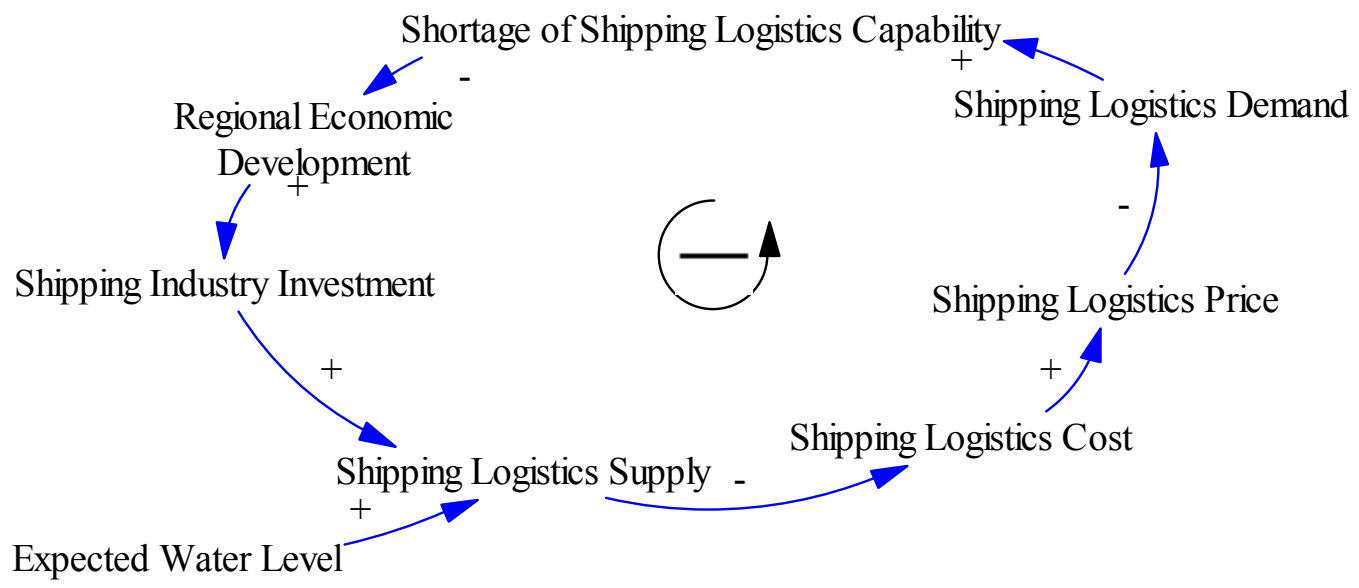

Fig.8. Demand and supply coordination ring of shipping logistics 


\section{Conclusion}

It studies the internal structure of the shipping logistics system based on system dynamics, it analyzes the influence of transfer process from water level to shipping logistics system. Analysis showed that water level as an exogenous variable shipping affects shipping logistics system through the impact on ship, waterways and ports, and this impact will be back to water level through a feedback mechanism, and finally affect water level through policy measures. 


\section{References}

[1] Zhang Shi-yu. Theoretical, Methodological and Empirical Studies on the Supply Analysis of Inland Water Transportation[D]. Wuhan University of Technology, 2003. 12-15.

[2] Zhong Yong-guang, Jia Xiao-qing, Li-xu. System Dynamics[M]. Beijing Science Press, 2009.

[3] Zhang Guo-wu, Jia Shun-ping. Transportation System Dynamics[M]. Southwest Jiaotong University Press, 1993. 